\title{
Procesos de recualificación urbana e imaginarios de la innovación. El caso Rosario, Argentina
}

Paula Vera. Consejo Nacional de Investigaciones Científicas y Técnicas (CONICET), Buenos Aires, Argentina.

RESUMEN | El objetivo de este artículo es reflexionar sobre cómo incide la idea de innovación -entendida como una nueva significación en las políticas públicas localesen los procesos de recualificación urbana. Con ese fin se conjuga la teoría de los imaginarios sociales con un análisis cultural, para tensionar la conformación discursiva del imaginario urbano dominante y los fenómenos de transformación de la ciudad de Rosario, que en la última década viene desarrollando proyectos urbanos tendientes a reestructurar y recuperar zonas degradadas a partir del reordenamiento de espacios y actividades. En este contexto se indagan los procesos de recualificación definidos por la noción de innovación como motor del cambio urbano: la Ciudad Joven y el Polo Tecnológico, en los cuales se evidencia la incidencia del modelo de innovación de triple hélice en las nuevas materializaciones producto de las transformaciones acaecidas.

PALABRAS CLAVE | renovación urbana, imaginarios urbanos, innovación tecnológica.

ABSTRACT | The purpose of this article is to reflect on how the idea of innovation, understood as a new significance in local public policies, affects the urban requalification processes. With this purpose, the theory of the social imaginary is conjugated with a cultural analysis to tense the discursive conformation of the dominant urban imaginary and the phenomena of transformation of the City of Rosario, which in the last decade, has been developing urban projects tending to restructure and recover degraded zones from the reclassification of spaces and activities. In this context we investigated the requalification processes defined by the notion of innovation as an engine of urban change: The Young City and the Technological Pole, in which evidence of the influence of the "Triple Helix" model of innovation is evidenced in the new materializations due to happened transformations.

KEYwORDs | urban renewal, urban imaginary, technological innovation. 


\section{Introducción $^{1}$}

En los últimos años, el término 'innovación' se instaló con fuerza en los discursos empresariales, políticos, periodísticos, académicos y científicos. Se presenta como el nuevo horizonte de expectativas donde, con optimismo, convergen esperanzas y promesas. La innovación resulta, entonces, un significante en el cual se fusionan y confunden múltiples sentidos; y, al mismo tiempo, una significación imaginaria consolidada que funciona como argumento y permite legitimar políticas públicas, normativas, actuaciones empresariales y ciudadanas de las más diversas. Esto es posible porque, al constituirse en un sentido dominante y hegemónico del imaginario actual, el término se naturaliza, lo que contribuye a invisibilizar los matices, conflictos y efectos adversos que implica en los procesos de reconversión urbana.

En el marco de lo señalado, consideramos necesario indagar la significación de lo que hoy se entiende por 'innovación', noción vinculada a las ideas de progreso y desarrollo, para intentar comprender cómo interactúa con ellas en la matriz sociocultural contemporánea que prefigura el campo de sentidos de las ciudades. ¿Cuáles son las discursividades, acciones, instituciones y materialidades que le dan cuerpo a la innovación? ¿Qué implicancia tienen en los modelos urbanos actuales? ¿Cómo se adaptan las ciudades a esta nueva significación? ¿Por qué tiene más influjo en ciertas culturas urbanas?

Al relacionar la innovación con las ciudades, una de las problemáticas factibles de ser abordadas es la recualificación de espacios degradados en pos de transformar la imagen de la ciudad para "adecuarla" a los modelos urbanos internacionales (Lacarrieu, 2010). En este sentido planteamos, a modo de hipótesis, que el imaginario urbanotecnológico en torno a la innovación influye material y simbólicamente en las transformaciones urbanas contemporáneas, delineando estrategias de marketing urbano, espacializando prácticas sociales, promoviendo estilos de vida, alentando ciertas subjetividades y construyendo determinados fragmentos espaciales dentro de la ciudad.

En este artículo nos proponemos analizar la incidencia de la idea de 'innovación' como nueva significación en las políticas públicas locales, en relación con los procesos de recualificación urbana emprendidos en la última década en la ciudad de Rosario. Para ello desarrollamos un abordaje crítico interpretativo de estos procesos, apoyado en los fundamentos de los estudios culturales urbanos y los imaginarios sociales. Como punto de partida general, sostenemos que los procesos de construcción social de lo urbano se sustentan en el entramado de sentidos que esa misma sociedad ha venido construyendo a lo largo de su historia, y que es a partir de ellos que se determina, en cada momento, si algo tiene valor o no para esa sociedad. Los imaginarios sociales (Castoriadis, 2003) conforman la trama significativa sobre la que se funda la construcción de la sociedad y de la realidad, que se materializa en diversas acciones, afectos, representaciones, discursos, imágenes, objetos, instituciones, leyes y valores.

$1 \longdiv { \text { Este trabajo es una adaptación de lo desarrollado en la tesis doctoral, financiada por el Consejo } }$ Nacional de Investigaciones Científicas y Técnicas (CONICET) mediante dos becas de formación de posgrado. 
En este punto, se hace necesario también considerar los aspectos históricos que permiten comprender tales composiciones de sentido. No se trata de constatar si un discurso es falso o verdadero, sino de comprender cómo se generan creencias y deseos que soportan determinadas prácticas, aparatos, instituciones y subjetividades; así como en qué contexto emergen ciertas definiciones que actúan sobre el imaginario social con un efecto de verdad incuestionable definiendo, al mismo tiempo, aquello que tiene validez y relevancia. En este sentido es que condicionan, por ejemplo, el desarrollo de políticas públicas de los gobiernos locales que hacen a los procesos de producción del espacio urbano. Por ello es posible analizar las vinculaciones simbólicas entre el imaginario urbano dominante, las formas de legitimación y las resistencias a ellas, a partir del análisis de ciertas herramientas, como los planes estratégicos, y ponerlos en tensión con las formas de construcción de territorialidades concretas. En este tipo de documentos es posible rastrear, recomponer e indagar significaciones que emergen como institucionalizadas, es decir, aceptadas y legitimadas, ${ }^{2}$ que sostienen y justifican los procesos de transformación urbana.

En Rosario ${ }^{3}$ se vienen desarrollando diversos proyectos urbanos tendientes a reestructurar y recuperar zonas degradadas a partir del reordenamiento de espacios, actividades y símbolos, orientados a renovar la imagen y el estilo de vida de la ciudad. Este caso resulta paradigmático, porque contribuye a comprender cómo se despliega el fenómeno urbano vinculado a la innovación en una ciudad del interior de la Argentina y, también, porque Rosario posee una retórica identitaria muy vinculada al progreso, el emprendedorismo y la innovación (Vera, 2013a). En este contexto analizaremos los procesos de recualificación urbana definidos por la noción de innovación como motor del cambio urbano y desarrollo económico: la Ciudad Joven y el Polo Tecnológico.

\section{La innovación como promesa de desarrollo colectivo}

Desde la modernidad, la idea de progreso impregnó el imaginario colectivo como promesa de mejora de la calidad de vida de toda la humanidad, de la mano de los avances tecnológicos. Civilización, orden, futuro y crecimiento fueron términos que acompañaron la conformación de una matriz cultural que, más allá de sus momentos de debilidad o las perspectivas más pesimistas al respecto, siguió vigente y mutando para adaptarse a nuevos tiempos y demandas. Después de la Segunda Guerra Mundial, la desconfianza en las tecnologías y la fe absoluta en el progreso crecieron (Cabrera, 2006; Díaz, 2003; Mumford, 2011; Schmucler, 1997), habilitando una serie de posiciones críticas. No obstante, la posterior crisis del Estado de

2 Por tal razón sostenemos que se trata del imaginario dominante, sin que ello signifique que se trata de un campo de sentidos homogéneo, estático o cerrado.

3 Rosario es una metrópolis del interior de Argentina que se encuentra en la zona central, $300 \mathrm{~km}$ al norte de la ciudad de Buenos Aires. Actualmente tiene 1.193.605 habitantes y una densidad de 631,5 habitantes $/ \mathrm{km}^{2}$; es la tercera ciudad de Argentina en relación con la cantidad de habitantes y la mayor ciudad de la Provincia de Santa Fe, con una población total de 3.199.537 habitantes y una densidad de 24 habitantes $/ \mathrm{km}^{2}$. Estos datos fueron obtenidos en el Instituto Nacional de Estadísticas y Censos (2010), http://www.indec.gov.ar/ 
bienestar, junto a la emergencia de las perspectivas que anunciaban el fin de las ideologías (Bell, 1964) y el fin de la historia (Fukuyama, 1992), prepararon el terreno para renovar el optimismo hacia el futuro y propiciar la emergencia de una nueva significación imaginaria que vendría a contener y renovar la fe en el progreso: el desarrollo. La mayoría de los discursos convergieron en la búsqueda del "desarrollo", como si la concepción misma de lo que se concebía como tal, los medios y los modos de alcanzarlo, no constituyeran en sí posicionamientos ideológicos. Desde la década de 1980 en los denominados países desarrollados, y hacia la década de 1990 en una geografía más extendida, la matriz de pensamiento y acción neoliberales favoreció e impulsó que el término 'innovación' se fuera consolidando como nuevo medio para alcanzar el desarrollo y el progreso.

El fortalecimiento político y cultural del neoliberalismo permitió arraigar ciertos sentidos, entre los que se destacan la libertad, el individualismo, la lógica empresarial en la esfera política, la inversión privada como fuente de transparencia en la gestión pública y la planificación estratégica como medio de conducir las sociedades al desarrollo. Esto impactó en que la administración pública y la planificación se considerasen más como herramientas técnicas que como medios políticos, lo que favoreció la consolidación y legitimación de diversos tipos de acciones tras las cuales estaba como argumento incuestionable el de la innovación. La fascinación que genera este concepto se relaciona con que orienta y da sentido a un futuro que se expresa cada vez más incierto (Alonso, 2013; Nowotny, 2011). Y, como sostiene Alonso (2013), es justamente su banalización lo que funciona como síntoma de la hegemonía de sentido.

Las perspectivas economicistas, tecnológicas y empresariales son las que dominan actualmente el paradigma de la innovación. Un autor de referencia es Schumpeter, quien se pronunció largamente sobre la problemática del desarrollo. ${ }^{4}$ Sin embargo, como explica Godin (2010), no es la única, y otros estudiosos que intentaron comprender la innovación desde aspectos sociológicos y antropológicos quedaron invisibilizados.

La innovación inicia su trayectoria en las discursividades hegemónicas contemporáneas para tornarse dominante en las últimas décadas, impulsada -y en muchos casos justificada- por la renovación tecnológica digital, que se tradujo en el despliegue de una economía globalizada y focalizada en el conocimiento, la información y los flujos financieros (Castells, 1997; Sassen, 1991).

El sentido primero del término 'innovación' refiere a la introducción de un invento -ya sea un producto, un servicio o un proceso- en la actividad económica. Se trata de una visión donde la innovación es validada exclusivamente "por" y "en" el mercado. Esta perspectiva, denominada 'economía de la innovación', ha puesto el foco en el abordaje del cambio tecnológico en las empresas y en la importancia ser estacionario y cuya principal característica es el proceso de "creación destructiva". En su análisis, el "empresario innovador" ocupa un rol central como agente que consigue imponer sus innovaciones en un medioambiente adverso, signado por la competencia y la destrucción creativa, en un proceso que continuamente revoluciona la estructura económica desde adentro. 
del rol que adquieren el entorno social y los territorios donde las mismas se localizan $^{5}$ (Schiavo, Dos Santos Nogueira \&Vera, 2013). En relación con el aspecto territorial, Castells (1995) destaca el rol central que desempeñan los "medios de innovación” en el futuro de las sociedades. Considera que las aglomeraciones donde se encuentran instituciones de conocimiento científico y técnico, empresas y trabajo cualificado constituyen las "calderas de la innovación en la Era de la información" (Castells, 1997, p. 83). En sintonía con estas ideas, Finquelievich (2007) sostiene que "el desarrollo de estos tipos de medios -innovadores- es no solo un factor decisivo para el desarrollo económico local, sino también una cuestión de prestigio social y político" (p. 67). Es decir, se considera la innovación como la clave del éxito o el fracaso, se erige como nuevo valor social que, a su vez, determina el desarrollo y el progreso de las ciudades.

El discurso académico como legitimador de las discursividades dominantes contribuye a consolidar este imaginario, que vincula innovación, desarrollo y tecnologías como las claves del éxito económico y social con miras al futuro de las ciudades, a la vez que delinea perspectivas sobre las políticas urbanas que se van materializando en la trama urbana. Esto también se evidencia en los discursos puestos en circulación por parte de los organismos internacionales. Otro ejemplo de la propagación de la idea de la innovación como aspecto positivo de cualquier iniciativa es que, para medir y elaborar políticas y programas tendientes a disminuir las brechas sociales, económicas y tecnológicas, se desarrolló un "Índice Mundial de Innovación” que

refleja, por una parte, la importancia fundamental que reviste la innovación como motor del crecimiento económico y la prosperidad y, por la otra, la necesidad de adoptar una perspectiva horizontal amplia de la innovación, que pueda aplicarse tanto a las economías desarrolladas como a las economías incipientes (...) El Índice Mundial de Innovación constituye un valioso instrumento de análisis comparativo que facilita el diálogo entre los sectores público y privado, del que pueden valerse los encargados de la adopción de políticas, los líderes empresariales y demás sectores interesados para evaluar el progreso a medida que avanza. ${ }^{7}$

En esta definición podemos ver con claridad una serie de aspectos vinculados a la idea hegemónica de innovación. Por un lado se la afirma, incuestionablemente, como motor de crecimiento, desarrollo y prosperidad, y se busca deslindarla de los contextos sociopolíticos, culturales y económicos, presentándola como la solución efectiva tanto para economías desarrolladas como para aquellas menos favorecidas. Por otra parte, se incluye al sector privado como socio necesario del sector público en el diseño e implementación de políticas innovadoras, al tiempo que se induce la carrera por la competencia entre ciudades como instrumento de análisis comparativo.

5 Son numerosos los trabajos acerca de la economía de la innovación que tienen bases en los aportes de Schumpeter y los realizados por la llamada economía neoevolucionista, conformada por autores como Nelson, Winter, Dosi, Freeman y Soete, entre otros.

6 The Global Innovation Index, www.globalinnovationindex.org/content.aspx?page=GII-Home

7 Club de Innovadores Públicos (CIP), Comentario a Informe - Indice Mundial de Innovación 2012, de InSEAd y Organización Mundial de la Propiedad Intelectual (ompi). http://bit.ly/2i9SFen 
$\mathrm{Al}$ igual que ocurrió con las ideas sobre desarrollo, las perspectivas sobre la innovación se presentan con dos grandes objetivos: el mejoramiento de la calidad de vida y la "evolución" del sistema económico capitalista. En una época en la que todo parece estar inventado, lo que se requiere es explotar la capacidad humana de la creatividad para agregar valor a esos productos: un valor que en sí mismo es intangible pero que, de alguna manera, termina siendo redituable a los sistemas económicos y financieros.

La actual fase de la innovación está ligada a un campo de sentidos que la sostienen. Entre ellos se destacan la participación, la diversidad, la flexibilidad, la interdisciplinariedad, la conexión del dominio social con el tecnológico, el elogio de la investigación y la formación continua, la colaboración entre universidad y empresas, la horizontalización de las jerarquías de mando, el trabajo en equipo y la organización en red (Alonso 2013; Augé, 2012; Fernández Rodríguez, 2007). Lo novedoso de este campo de sentidos es que impulsa la cooperación entre el Estado y las empresas allí donde la "dimensión colectiva de la innovación" ha comprobado su eficacia: en el sector de I+D (Augé, 2012). Se puede afirmar, entonces, que la "innovación" se presenta como un sueńo colectivo, un fenómeno mundial producto de una sucesión lógica y racional del desarrollo técnico y revestido de un amplio optimismo tecnológico, cuando, en realidad, es un discurso que surge como un deseo muy vinculado al sector empresarial.

Concordamos con Alonso y Fernández Rodríguez (2011) en que la mayor transformación que ha sufrido el imaginario sobre la innovación social es el desplazamiento desde estar vinculada exclusivamente a los cambios sociales y la ampliación de derechos sociales, a ser concebida como la capacidad que poseen las sociedades actuales de metamorfosearse para adaptarse y volverse más competitivas en el ámbito económico. Es justamente este proceso el que se analiza en este trabajo, donde se intenta dar cuenta de cómo se resignifica y reconstruye materialmente la ciudad para adaptarse a los nuevos parámetros de competitividad. Esto, al mismo tiempo, interrogado a partir de dos modelos de producción de la innovación que nos permitirán analizar los imaginarios que se ponen en juego en la reconversión urbanística. En primer lugar, el modelo denominado "triple hélice", que concibe un proceso de producción de conocimiento e innovación que involucra a los gobiernos, las universidades o centros de investigación y las empresas. Así, las universidades funcionan como productoras de conocimiento, el Estado como oferente de un marco regulador apropiado y las empresas, originando oportunidades de negocio y promoviendo las innovaciones tecnológicas. En general, este modelo encuentra particular aplicación en el nivel regional, a través de proyectos para potenciar polos y parques tecnológicos (Schiavo et al., 2013). Por otra parte se encuentra el modelo de "cuádruple hélice", que sostiene una postura de innovación abierta y basada en los usuarios (Tuomi, 1999). Aquí se busca incorporar al usuario en el proceso de co-creación de conocimiento ya no como actor observado, sino como partícipe de la formulación de ideas, desarrollo y evaluación de productos (Serra, 2010).

Como han estudiado, entre otros, Echeverría (2013), Echeverría y Merino (2011) y Gurruxtaga (2011), los deslizamientos semánticos en torno al concepto de innovación pueden ser estudiados en los planes, manuales y políticas impulsadas 
por organismos internacionales (Organización de las Naciones Unidas [onu], Organización para la Cooperación y el Desarrollo Económicos [OCDE], Oficina Europea de Estadística [Eurostat]). Hay que tener en cuenta que en la conformación y legitimación de imaginarios, estos organismos tienen un peso específico de envergadura. Por ello, resulta propicio analizar documentos de políticas públicas en otras escalas y geografías para dar cuenta de la circulación y apropiación de estas ideas en otras latitudes, porque la persuasión de la innovación se traduce en políticas y acciones concretas.

El caso de Rosario, que analizaremos a continuación, constituye un caso testigo de cómo esta discursividad sobre la innovación impregna las políticas públicas y, además, se traduce en transformaciones materiales concretas. Se trata de avizorar un proceso que se ha puesto en marcha también en otras ciudades, como Buenos Aires y Medellín, por mencionar algunas. Sin embargo, en este caso, indagaremos cómo se materializa el desplazamiento de una ciudad decimonónica que era imaginada y relatada como ferroportuaria e industrial, a una ciudad del siglo xxi que pone su foco en la cultura, la creatividad y las tecnologías, consolidando su imaginario urbano ligado a la innovación como marca de identidad.

\section{El arribo de la innovación a Rosario}

La vinculación entre innovación y políticas públicas se fue estrechando desde la década de 1990 en todos los países "en vías de desarrollo" a través del neoliberalismo. La retórica de la innovación (Echeverría, 2013) acarrea las ideas de cambio social, avance tecnológico, progreso y desarrollo humano. No incluir la "innovación” en las políticas públicas podría significar, entonces, quedarse al margen del progreso, (Schweinheim, 2011) o del presupuesto, como asegura Echeverría (2013). Al mismo tiempo, el discurso de la innovación social plantea la necesidad de la intervención del Estado para tomar medidas que favorezcan la integración de las sociedades en la actual economía del conocimiento (Alonso \& Fernández Rodríguez, 2011). Y no solo como planificador, sino también como proveedor de capital intelectual, financiación y estructuras (Peters, 2008).

Entonces, el escenario se vuelve más complejo, porque no se trata de un neoliberalismo que busca la minimización del Estado, sino de uno que promueve determinado modo de intervención para propiciar la innovación, augurando un éxito que se expone como inevitable.

Iniciativas, cursos, rankings y premios sobre gestión pública innovadora colmaron el escenario político. Sin embargo, más allá de las promesas que rodeaban a la innovación y las políticas de desarrollo, la inclusión y la equidad social siguieron estando ausentes en los resultados esperados. Las políticas "innovadoras" de los noventa fueron un conjunto heterogéneo de programas sociales focalizados, descentralizados y acordes a resultados. Las herramientas disponibles para impulsar la reforma o modernización del Estado provinieron principalmente del ámbito empresarial. De este modo, la eficiencia, la transparencia y la solidez, valores ya consolidados de la esfera privada, ingresarían a las estructuras públicas a partir de la implementación de nuevas lógicas y prácticas sociales. Así, la promesa de la renovación del Estado 
a partir de la confianza que despertaban las técnicas fabricadas "por" y "para" las empresas, estrechó las lógicas estatales y empresariales. Los planes estratégicos se fortalecieron como herramientas técnicas de planificación política y urbanística. $\mathrm{Su}$ implementación también puso de manifiesto cierto imaginario urbano que condujo, a su vez, a la formulación de determinados modelos de ciudad. El más emblemático es el denominado Modelo Barcelona, ${ }^{8}$ que funciona como referente de este tipo de planificaciones.

En Argentina, las principales ciudades metropolitanas cuentan con planes estratégicos. Si bien algunos de ellos surgieron en la década de 1990, en los últimos años este tipo de planificación ha tenido un nuevo impulso. En Buenos Aires este proceso se inició en 1994 con la elaboración de diversos documentos que formalizaron el Plan Estratégico Buenos Aires 2010. En Córdoba, el primer Plan Estratégico de la ciudad se creó en 1999 y en 2005 se presentó una versión renovada.

En Rosario se refleja un proceso similar. En un contexto de crecimiento de la economía flexible, de la tecnificación y modernización de la gestión pública, se desarrolló el Plan Estratégico Rosario 1998 (PER 1998)9 como hoja de ruta de la gestión y las políticas públicas locales, y en 2010 se lo actualizó bajo la denominación Plan Estratégico Rosario Metropolitano (PERM) ${ }^{10}$. A estos se agrega el Plan Urbano Rosario 2007-2017 (PUR), ${ }^{11}$ que también tiene lineamientos estratégicos urbanísticos, entre los cuales destaca la recualificación de la zona costera y los espacios que serán jerarquizados mediante convenios público-privados.

Rosario es un municipio que viene orientando sus políticas urbanas en consonancia con el prototipo de planificación estratégica desde 1998, favorecido por la continuidad de una gestión política socialista desde 1996 a la fecha, única en el país. Esto permite poner en relieve las paradojas que venimos describiendo con relación a lo político e ideológico y cómo estos aspectos quedan subsumidos en las prácticas innovadoras y urbanas actuales.

Declarada ciudad en 1852, al tiempo que su puerto era habilitado para el comercio internacional, entre finales de siglo xix y principios del xx Rosario se consolidó como segundo nudo ferroportuario de la Argentina, complementando esta actividad con la conformación de un cordón industrial en su área metropolitana, siempre sensible a los vaivenes económicos nacionales e internacionales. En este mismo periodo se consolidaron muchas de las representaciones urbanas aún dominantes. La mitad de su composición demográfica era de inmigrantes europeos. Esto, sumado a las disputas políticas con el gobierno nacional, favoreció la

8 Este modelo ha sido profundamente criticado por diversos especialistas que denuncian los efectos que estos procesos urbanísticos tienen para los propios habitantes de la ciudad que se ven cada vez más segregados, controlados y restringidos para acceder a la vida urbana que se propone en los espacios recualificados (Capel, 2007; Delgado, 2007).

9 Municipalidad de Rosario (1998), Plan Estratégico Rosario 1998, http://www.rosario.gov.ar/sitio/ verArchivo?id=4718\& tipo=objetoMultimedia

10 Municipalidad de Rosario (2010), Plan Estratégico Rosario Metropolitana | PERM+10, http:// echerosario.blogspot.cl/2010/05/plan-estrategico-rosario-metropolitana_23.html

11 Municipalidad de Rosario (2011), Plan Urbano Rosario 2007/2017, http://www.rosario.gov.ar/ web/ciudad/planeamiento-urbano/plan-urbano-rosario/libro-plan-urbano-rosario-2007/2017 
emergencia de ciertas mitologías locales: "Rosario, hija de su propio esfuerzo" es, quizás, la que mejor sintetiza el relato sobre la propia identidad urbana. Aquí se condensan las ideas de progreso, trabajo, poder de emprendimiento y autosuficiencia que actualmente permiten comprender la repercusión social que tiene la innovación en esta ciudad (Vera, 2014).

Las transformaciones económicas, políticas y sociales del país acarrearon una crisis que se profundizó hacia fines de la década de 1990, para terminar de eclosionar en el periodo 2001-2002. La metamorfosis era indispensable y hacía necesario entablar un diálogo con el ámbito privado empresarial. Con esta premisa, en 1996 se constituyó la Junta Promotora del Plan Estratégico Rosario, que incluía destacadas instituciones y referentes del empresariado local. También se convocó a especialistas y consultores internacionales, como Jordi Borja y Joan Alemany Llovera. ${ }^{12}$ Esto permitió dar cuenta de la transnacionalización de ideas y modelos urbanos que, a partir de una imagen de éxito promovida con estrategias de marketing, lograron devenir en deseos colectivos de ciudades con diferentes contextos y realidades.

En 1998 se publicó el Plan Estratégico Rosario. Allí se diagnosticaba el agotamiento de la ciudad industrial y el declive del régimen de acumulación, que provocaron una crisis urbana que se intensificó en la primera mitad de la década. Para enfrentarla, se necesitaba una ambiciosa transformación, y el objetivo propuesto fue consolidar "una ciudad abierta, plural, integradora, moderna y creativa, que ocupe un lugar relevante entre las ciudades latinoamericanas" (PER 1998, p. 5).

El PER se presentaba como el producto de acuerdos y consensos de diversos actores públicos y privados, consolidándose como "una herramienta de gestión de la ciudad" (p. 5), "para potenciar su desarrollo" (p. 16). Al mismo tiempo, se expusieron las ideas sobre la técnica de la "planificación estratégica", considerada una metodología flexible, moderna, participativa y democrática, condiciones necesarias para enfrentar los tiempos contemporáneos (pp. 16-18). La perspectiva despolitizada y desideologizada prevalecía y se expresaba a partir de la idea de acuerdo, a partir de la cual se construía la imagen de una ciudad homogénea donde se perseguían los mismos intereses y, para alcanzarlos, se podía emplear los mismos medios.

El PER 1998, una novedosa herramienta de gestión propia del mundo empresarial, resulta ser un campo fecundo para analizar los imaginarios urbanos dominantes, las ideas en torno a lo que significa "ser innovadores" y cuáles son las acciones, instituciones y materialidades que le darían cuerpo a la innovación. Por ello, no se analizarán las políticas de innovación concretamente, sino que se indagará en la idea de innovación como nueva significación en las políticas públicas locales. Se trata de

12 Jordi Borja, sociólogo, geógrafo y urbanista catalán, teniente de alcalde (vicealcalde) de Descentralización y Participación ciudadana de Barcelona (1983-1987) y vicepresidente ejecutivo del Área Metropolitana de Barcelona (1987-1991), se ha desempeñado en el ámbito académico y también en el de las consultorías. Participó como asesor en el proceso de desarrollo del Modelo Barcelona, en la reconversión de Puerto Madero en Buenos Aires y en los planes estratégicos de Río de Janeiro, Bogotá, Medellín y Rosario. Joan Alemany Llovera, economista y profesor, también se desempeńa como consultor en planificación urbana y portuaria, con trabajos de consultor en la reconversión de espacios portuarios en Marsella, Bilbao, Montevideo, Rosario y Valparaíso. http://www.aippyc.org 
un término que, por un lado, funciona como aglutinador de una amplia diversidad de actividades, instituciones y estilos de vida; y por otro se encuentra fundamentalmente ligado al desarrollo económico urbano.

\section{La innovación como concepto aglutinante y motor del desarrollo local}

En el PER 1998 se establecía que una nueva ciudad estaba llegando con el nuevo siglo. Esta "nueva ciudad" se alejaba del modelo industrial que dio entidad a la ciudad moderna, para insertarse en otras escalas. Tal idea aparece en estrecha relación con la 'innovación' como concepto que permite la convergencia de los cambios tecnológicos, sociales, políticos, económicos y culturales, en tanto aspectos del desarrollo local de la "nueva agenda” público-privada que proponía el Plan. En consecuencia, uno de los objetivos que se perseguía era incrementar la vinculación de Rosario con la región y el mundo, aprovechando "la revolución científico-tecnológica (...) para posicionarse ventajosamente frente a las innovaciones. En este sentido, será útil potenciar nuevas relaciones entre Estado y sociedad civil, incorporando gerenciamiento público-privado. La capacidad intelectual y los talentos creativos de la ciudad deberán ser revalorizados, para ponerlos al servicio de la transformación” (PER 1998, p. 23). Es explícita la confianza y el optimismo tecnológico que, sumado al gerenciamiento público-privado, podrían expandirse en la ciudad facilitando las transformaciones necesarias para emprender el camino hacia el desarrollo por medio de la innovación. Además, según el diagnóstico del Plan, Rosario contaba con un buen posicionamiento respecto a la imagen de ciudad creativa e innovadora. En todos los planes analizados se forja la idea de Rosario como ciudad cultural, creativa, cuna de talentos. ${ }^{13}$ Este diagnóstico no solo atiende a los rasgos de lo que exige el modelo urbano actual. También se vincula con la configuración histórica de la identidad local. Son numerosos los relatos de viajeros de fines de siglo xix y principios del xx (Videla, 1999) que destacaban la actividad comercial de la ciudad en contraposición a su falta de actividades culturales y artísticas. Desde entonces, diversos actores y estrategias se orientaron a revertir esta falta. ${ }^{14}$

Nueva ciudad, nuevas tecnologías y nuevas técnicas de gestión se entrelazan como promesas para satisfacer las expectativas colectivas de construir la ciudad del futuro, que se presenta (casi) inevitable. Esos deseos colectivos se depositan como esperanzas en torno a la innovación como la clave para su realización, ya que "lo innovador [es] lo que puede cambiar, aquello que hoy no está pero que la ciudad y sus actores más visionarios comienzan a imaginar para su futuro" (PER 1998, p. 103). Por otra parte, y a pesar de la imagen elaborada de Rosario como "una" ciudad, cuando se habla del perfil de la nueva ciudad, se naturalizan las desigualdades al afirmar que "esa ciudad se irá construyendo junto a sus propias contradicciones

13 Esto refiere, principalmente, a algunos artistas destacados de la ciudad.

14 Profundizar este tema excede las limitaciones del artículo. Sin embargo, es importante mencionarlo para comprender las condiciones de posibilidad que habilitan la emergencia e institucionalización de ciertas significaciones. Desde fines del siglo xIx, distintos referentes de la burguesía local comenzaron a componer sus colecciones de arte privadas y apostar a actividades culturales para revertir esta imagen de ciudad sin cultura. 
sociales, económicas y territoriales. (...) Es que los actuales modelos de sociedad no garantizan la inclusión de todos los sectores sociales, la fortaleza de la economía local y sus empresas, ni el equilibrio entre sus diferentes espacios urbanos" (PER 1998, p. 103). Se asume la exclusión como mal inevitable del modelo, un modelo que se presenta como estructural y ajeno a la política. No obstante, a continuación se deposita en la competitividad del desarrollo territorial las oportunidades para el progreso de todos los rosarinos (PER 1998, p. 103). Que la competitividad conduzca a generar oportunidades de progreso para todos es una ficción ligada a la idea liberal denominada "efecto derrame", que postula que a partir del progreso de algunos, los beneficios rebalsarían la pirámide social beneficiando, por defecto, a quienes se encuentran en la base, es decir, en condiciones más desfavorables. El Plan es la representación de la ciudad deseada (en apariencia) por todos los ciudadanos, donde se remarca su orientación estratégica y despolitizada.

Junto con el Plan Estratégico Rosario 1998, para hacer posibles los cambios hacia el desarrollo de la ciudad se expone la necesidad de modificar el modelo de gestión existente y se propone el programa "Autonomía local, modernización y descentralización municipal”. Se señala al respecto que los procesos de modernización de los municipios "producen algunas señales de innovación en los gobiernos locales: la descentralización de la ciudad para encontrar respuestas localizadas; la incorporación de nuevos sistemas de información y comunicaciones; la aparición de formas novedosas de gestión público-privadas" (PER 1998, p. 70). Estas discursividades y aspiraciones son posibles en el marco de la reforma constitucional realizada en 1994, en la cual se incorpora la descentralización como una política de Estado. La racionalización técnica de la administración pública a través de distintos artefactos y tecnologías organizativas se convierte así en la materialización del imaginario tecnológico en el ámbito de la gestión pública. Esta ciudad, que en la modernidad se constituyó como el espacio del progreso, en la contemporaneidad refuerza su rol, apuntalada por las políticas de descentralización y la teoría de los gobiernos locales. La innovación vinculada con la reforma estatal, la incorporación de nuevas tecnologías y los potenciales productos que se pueden generar explotando las capacidades creativas de los ciudadanos, permiten nuclear las esperanzas colectivas en este término que funciona como una "nueva" ensońación social.

Las diversas temporalidades convergen en un acuerdo pacífico. El pasado y el futuro entablan un diálogo que se expone sin conflictividades en "una dialéctica entre tradición e innovación" (PER 1998, p. 43). Ese pasado es reconstruido a partir de ciertas representaciones de la ciudad donde destacan la idea del trabajo y la ciudad como hija de su propio esfuerzo, para la cual el trabajo es el factor básico de progreso e integración social. El pasado colmado de trabajo que en los noventa se añoraba, permitía incentivar las esperanzas colectivas de recuperación y retorno a aquello que se presenta como "natural" para una ciudad movida por la industria y el comercio. Hacia el futuro, se busca hacer de Rosario un centro regional de transportes y servicios que recupere su imagen de ciudad laboriosa y pujante (PER 1998, p. 43). Para el desarrollo de estos "sueños" se diagramó una línea denominada Ciudad del Trabajo, que ya no se vincula con las actividades y las materialidades que 
marcaron la ciudad industrial; lo que se propone es más bien una ciudad orientada a la nueva economía flexible, de servicios, de conocimiento y global.

Ante el cambio de época, el futuro se vislumbra lleno de oportunidades y la innovación emerge como el motor de la anhelada recuperación económica. "Nuevas inversiones públicas y privadas de magnitud proyectan convertirse en dinamizadoras de la economía y el empleo locales (...) orientando las tendencias regionales hacia actividades productivas innovadoras en tecnología, logística, marketing, diseño, entre otras" (PER 1998, p. 27). La necesidad creciente de innovar para ser más competitivos acerca al sector público y al privado para trabajar de manera coordinada a fin de lograr este objetivo que es, en definitiva, una promesa para alcanzar el desarrollo.

\section{Construyendo la ciudad creativa}

La flexibilización económica que implica el pasaje hacia una economía de producción de bienes intangibles, como el diseño y la moda, repercutieron fuertemente en las estructuras de las economías urbanas. Gran parte de la producción de la ciudad se basa en la promoción del arte, la cultura y la creatividad relacionados con los sectores fuertes de la nueva economía: alta tecnología, finanzas y servicios (Sennet, 2013). En este contexto, la ciudad creativa ${ }^{15}$ se consolida como significación dominante dentro del imaginario urbano contemporáneo. ${ }^{16}$

La ciudad creativa es un producto derivado del paradigma de la economía creativa emergente en los noventa y que tiene entre sus antecedentes los desarrollos realizados en las industrias culturales en la década de los cuarenta y la economía del arte de los setenta (Herrera Medina, Bonilla Estévez \& Molina Prieto, 2013). Entre los elementos que caracterizan la ciudad creativa se destacan las industrias culturales, la arquitectura patrimonial, los acontecimientos urbanos como festivales y eventos que favorecen el turismo, espacios públicos integradores (Casián Yde, 2012; Fonseca \& Kageyama, 2009; Yúdice, 2008) y la intervención focalizada para recuperar áreas abandonadas (Lerner, 2009).

Hacia esta economía de la creatividad y su consecuente modelo urbano se orientan muchas estrategias del PER 1998 y el PERM 2010, que toman la innovación como medio de reconstrucción de la ciudad. Para ello se esgrime la ciudad de la creación como línea de trabajo que conforma el núcleo de desarrollo creativo de la ciudad, el cual permite ir divisando las materializaciones urbanas que se concretan a partir de la incidencia que tienen la innovación y la creatividad en el imaginario urbano contemporáneo. El objetivo es afianzar Rosario como referente regional en la creación artística, el diseño y la producción científico-tecnológica, reforzando

15 Término desarrollado por Richard Florida (2002, 2005, 2009), junto al de clase creativa, como elementos claves del desarrollo de las ciudades en la actualidad. Florida se constituyó en un consultor internacional y sus ideas han tenido mucha incidencia en políticas y gestiones de diversas ciudades de Europa y Estados Unidos.

16 En 2004, la Unesco creó la Red de Ciudades Creativas, con el objetivo de aprovechar el potencial creativo para el desarrollo económico, social e inclusivo de las ciudades que formen parte de dicha red. 
su centralidad creativa y cultural en la región, promoviendo la actividad artística y cultural, potenciando sus vocaciones creativas e innovadoras y estimulando el conocimiento, las actividades científicas y el desarrollo tecnológico (PER 1998, p. 94). Aquí se puede percibir la centralidad que adquieren las subjetividades, es decir, para construir la ciudad creativa se necesitan sujetos creativos e innovadores. En este sentido, el Estado municipal desarrolla acciones, espacios y proyectos que favorecerían la emergencia y la permanencia de estas "vocaciones".

La necesidad de consolidar Rosario como una ciudad creativa respondería a dos motivos. Por un lado, porque, según la imagen del pasado y el presente que se construye, la ciudad es "generadora de talentos creativos en las más diversas manifestaciones del arte, la cultura y la producción científico-técnica. Creadores que, aún en condiciones adversas, conquistan un espacio en la geografía de la creatividad" (PER 1998, p. 95). Por otro, se encuentra el fundamento económico que sostiene que en los últimos años se ha consolidado la relación cultura-innovacióncreatividad-economía y, como prueba de ello, se menciona la creciente relevancia de las industrias culturales y de diseño. Estas actividades permitirían revitalizar la ciudad porque "constituyen elementos indispensables de competitividad (...). La capacidad de creación e innovación de una ciudad constituye no solamente un elemento dinamizador interno, sino también un factor importante de atracción externa" (PER 1998, pp. 95-96). Surge así la idea de formar parte de "la geografía de la creatividad", desarrollando un sistema de relaciones sinérgicas entre identidad urbana, sueńos colectivos, imagen de ciudad y despegue del desarrollo económico local. El mecanismo para ello sería promover la producción, circulación y comercialización de la creatividad y la innovación de actores locales a través de las "industrias culturales" y de un "polo de tecnología e innovación”, que permitan articular esfuerzos públicos y privados para consolidar la ciudad como nodo productivo e innovador de la región. En este contexto se diseñó una serie de proyectos orientados a materializar la "ciudad creativa" soñada y deseada desde la discursividad oficial. Entre ellos destacan la creación de "festivales y eventos", la "preservación del Patrimonio Urbano y Arquitectónico", ${ }^{17}$ la "creación de un sello discográfico municipal", "carreras universitarias de diseño" y el "Polo Tecnológico". Estos proyectos están en sintonía con las características generales que revisten las definiciones difundidas y aceptadas que mencionamos sobre lo que puede considerarse una ciudad creativa.

En el Plan Estratégico Rosario Metropolitano (PERM) de 2010 se retoma esta línea, incorporando algunas modificaciones. La ahora denominada Metrópolis de la Creación y la Innovación tiene el objetivo de posicionarse como polo de innovación, educación y cultura en el Mercosur, para lo cual plantea el desarrollo de proyectos y políticas culturales de diversa índole ${ }^{18}$ que van fusionando lo creativo y lo recreativo de la ciudad.

17 Sobre este aspecto he profundizado en "Estrategias turísticas y patrimoniales: su incidencia en la configuración urbana. El caso Rosario, Argentina” (Vera, 2015).

18 Ciudad Digital, Puerto de la Música, Franja Joven, Usina Digital Ceroveinticinco, La Ciudad del Bicentenario, Biblioteca del Bicentenario, Archivo Histórico de Rosario, Museo de la Memoria, Museo de Arte Oriental, Centro de Estudios Latinoamericanos Ernesto "Che" Guevara, Centro de Enseñanza del Idioma Español, Complejo Astronómico de Rosario, Acuario Rosario, Foro de Educación, Redes de Conocimiento, Bio Rosario, La Ciudad del Talento (perm 2010, p.159). 
En síntesis, las ciudades creativas e innovadoras se van haciendo lugar en las políticas públicas delineando ciertas espacialidades que materializan los símbolos y valores del imaginario tecnológico urbano: las industrias culturales y de diseño, por un lado, y los polos científico-tecnológicos, por otro, que en conjunto, como veremos a continuación, tienen una incidencia concreta en las formas que va adquiriendo la ciudad, al constituir dos nuevas centralidades urbanas.

\section{Industrias culturales: primer objetivo de recualificación}

En Rosario se vienen desarrollando diversos proyectos urbanos tendientes a reestructurar y recuperar zonas degradadas a partir del reordenamiento de espacios y actividades. Estos proyectos, delineados en los planes estratégicos (1998 y 2010) y el Plan Urbano Rosario 2007-2017 (PUR), están orientados a remodelar tanto la materialidad como la imagen de una ciudad que busca adecuarse a un modelo urbano contemporáneo de urbe cosmopolita, dinámica, innovadora y bella, para ser consumida y visitada.

Se consideran 'industrias culturales' aquellos sectores que están directamente involucrados en la creación, producción y distribución de bienes y servicios que son de naturaleza cultural y que están usualmente protegidos por el derecho de autor. Es decir, que su valor económico primario deriva de su valor cultural y tienen el potencial para la creación de riqueza y empleo a través de la generación y explotación de la propiedad intelectual (Quartesan, Romis \& Lanzafame, 2007). La complejidad y la importancia de este tipo de industrias radica en que constituyen una fuente de identidad, al mismo tiempo que, por tratarse de un sector dinámico, atraen significativas inversiones, que vienen teniendo cada vez mayor impacto en las economías regionales y locales (García Canclini, 2002). Es por eso que los gobiernos -nacionales, provinciales y locales- desarrollan continuamente políticas destinadas a proteger e impulsar su desarrollo. ${ }^{19}$

En el ámbito local, y en concatenación con proyectos nacionales y provinciales, ${ }^{20}$ el mayor impulso en esta área se dio en los últimos cinco años a partir del trabajo conjunto entre la Municipalidad de Rosario y el Ministerio de Innovación y Cultura provincial.

19 En el caso argentino, desde el Ministerio de Industria de la Nación se asegura que entre 2004 y 2012 las industrias culturales pasaron de representar el 2,4\% al 3,8\% del PBI nacional. Esto implicaría que producen, aproximadamente, 56.000 millones de dólares anuales y generan 300.000 puestos de trabajo directos, lo que representa el $2 \%$ del total del empleo formal registrado.

20 A nivel nacional se creó el Plan Nacional de Diseño, que busca facilitar la introducción del diseño y la innovación en la industria para mejorar la competitividad y posicionar los productos locales en el exterior, otorgándoles valor agregado. A esto responde también la creación del Mercado de Industrias Culturales Argentinas, orientado a poner en contacto a los diferentes actores de estas industrias para facilitar la generación de negocios, el intercambio de información y la presentación y difusión de la producción local en las principales empresas nacionales y del mundo. Por su parte, la provincia de Santa Fe creó el Ministerio de Innovación y Cultura, del cual depende el Programa Industrias Culturales, que tiene como objetivo garantizar el acceso, la circulación y accesibilidad de bienes culturales de calidad, creando sistemas de fomento, apoyo a los creadores, producción de contenidos y una red de circuitos potentes y creativos en el territorio. 
Uno de los impactos urbanos más destacados con relación a las industrias culturales ha sido la puesta en marcha de un proceso de recualificación de los galpones de depósito del antiguo puerto ubicado en el centro de la ciudad, en la zona del Monumento a la Bandera (figura 1), con el proyecto denominado Ciudad Joven. Este apunta, fundamentalmente, a hacer converger cultura, innovación, tecnologías, diseño y juventud como nodo destacado de la "nueva" ciudad, recuperando, a su vez, un espacio central en la costa ribereña (figura 2).

FIGURA I | Proyecto de reconversión de galpones portuarios

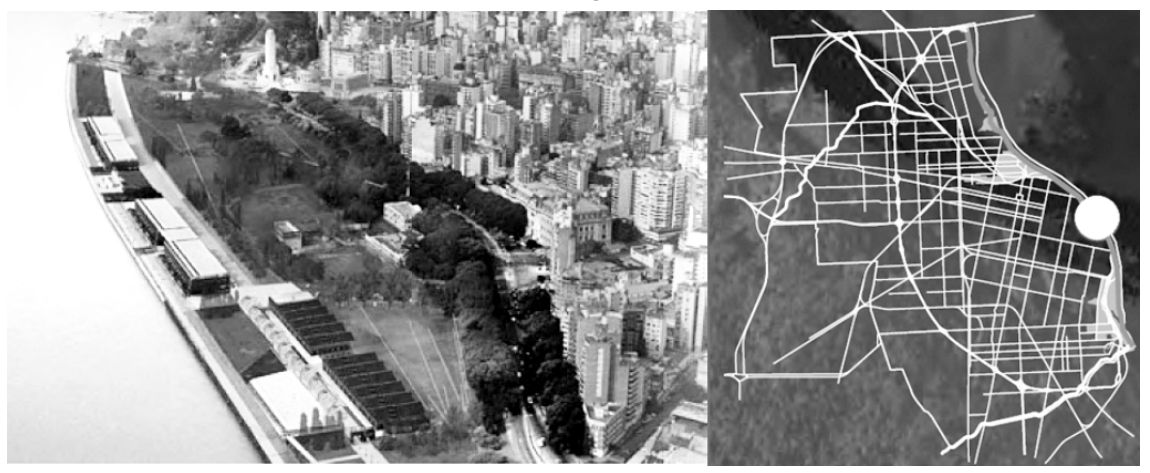

FUENTE ELABORACIÓN PROPIA A PARTIR DE PLAN URBANO ROSARIO 2007-20I7, PP. 236-240

FIGURA 2 | Proceso de reconversión galpones portuarios: 2008, 2012, 2014

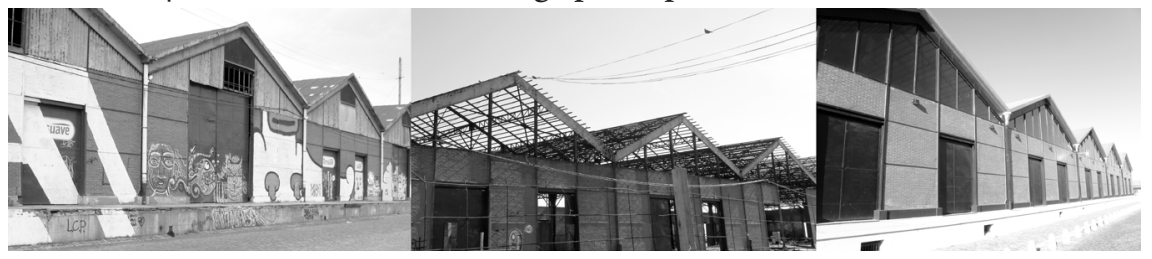

FUENTE CAPTURA PROPIA, 2008, 20I 2, 20I4, RESPECTIVAMENTE

Allí se complementan las instalaciones ya en funcionamiento (figura 3) -Centro de la Juventud y Centro de Expresiones Contemporáneas-, donde se realizan muestras y eventos culturales focalizados en las artes, la cultura local y las tecnologías.

En el PUR 2007-2017 se detallan los proyectos de recualificación para cada galpón y su área circundante. ${ }^{21}$ Estos espacios "apuntan a desarrollar el potencial del mercado cultural de Rosario a partir de la creación de nuevas estructuras de apoyo" (PER 1998, p. 100). Entre los proyectos que se radicarán en este nuevo espacio destaca la Usina Digital Ceroveinticinco, destinada a funcionar como incubadora de industrias culturales de diseño y tecnología gestionada y desarrollada por jóvenes (PERM 2010, p. 165). Si bien este proyecto fue delineado por el gobierno local, las obras fueron desarrolladas y financiadas por el gobierno provincial.

21 El área comprendida abarca $126.000 \mathrm{~m}^{2}$ de los cuales 12.000 son cubiertos (La Capital, $11 / 1 / 2013)$. 


\section{FIgura 3 | Primera reconversión. Centro de Expresiones Contemporáneas}

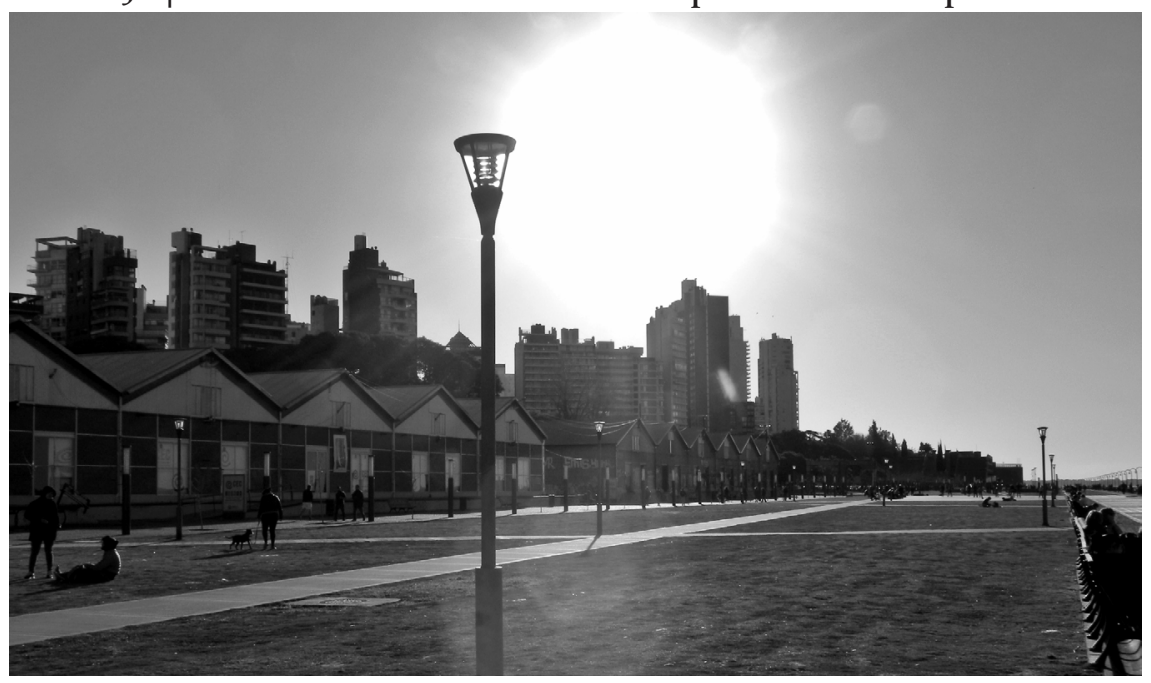

FUENTE CAPTURA PROPIA, 2014

La continuidad de las denominaciones de estos espacios como "galpones" busca sostener y, también, evidenciar el rasgo de ciudad portuaria e industrial que compone el imaginario urbano del pasado de Rosario. A diferencia del siglo pasado, ahora alojan actividades y productos propios de una ciudad que busca mostrarse creativa y de vanguardia. En este sentido, hay propuestas diferentes en cada uno. ${ }^{22}$ En el Galpón 11 se planificó una escuela de rock y la Escuela de Artes Urbanas, que viene funcionando desde 2001. Fue inaugurado finalmente en junio de 2015 gracias al aporte económico de una empresa privada, ${ }^{23}$ lo cual se enmarca en la modalidad "público-privado" ya característica de la gestión local. En el Galpón 13 funcionaría una "fábrica cultural" de diseño y artes de producción de objetos. En el 15 , talleres de malabares, trapecio y clown, y un "campamento digital" con salas de grabación de audio y video y salón de usos múltiples. Y, por último, en el Galpón 17 se emplazaría un restaurante y un bar cultural. ${ }^{24}$ En este caso se suscitaron diversos

22 Véase al respecto Santa Fe / Cultura / Espacios Culturales / Ciudad Joven, en https://www.santafe. gov.ar/index.php/web/content/view/full/191797/(subtema)/93703

23 La empresa aseguradora San Cristóbal donó 3 millones de pesos argentinos en el marco de su $75^{\circ}$ aniversario. Este aporte hizo posible la inauguración del Galpón ahora denominado Espacio 75. También se contó con la participación activa de tres asociaciones de músicos independientes ( $L a$ Capital, 27/6/2015).

24 En relación con la vida cultural urbana, en los últimos dos años se ha recrudecido un conflicto que puede leerse a modo de paradoja. Desde 2014 se vienen clausurando e impidiendo habilitaciones de bares y centros culturales. Concretamente no hay ordenanza que contenga el tipo de actividades que se practican en estos espacios. En consecuencia, numerosos espacios se han visto obligados a cerrar sus puertas. En respuesta se creó el ECur (Espacios Culturales Unidos de Rosario), que reúne a todos los bares y centros culturales de estas características para impulsar una legislación que permita su funcionamiento. Este tema merecería un análisis más exhaustivo, pero su mención en este apartado tiene la intención de mostrar cómo, por un lado, la retórica de Rosario como 
conflictos, ya que el Municipio se negó a enviar los pliegos de las licitaciones para la reconversión del área gastronómica al Poder Legislativo local. ${ }^{25}$ Esto se enmarca en una situación previa de irregularidades en las concesiones gastronómicas realizadas en toda el área ribereńa, en la cual se encuentran numerosos establecimientos emplazados en los espacios públicos.

Es interesante destacar que este proceso de reconversión no contó con movilizaciones de resistencia por parte de la ciudadanía. ${ }^{26}$ Solo hubo algunas expresiones de descontento y desconfianza por parte de miembros de la Escuela de Artes Urbanas que ya funcionaba en los galpones, y que ya retomaron sus actividades. La falta de resistencia pudo haberse debido a que se trataba de espacios en su mayoría abandonados o en malas condiciones edilicias, por lo cual su recuperación y puesta en valor se vieron acompañadas de un acuerdo implícito con la ciudadanía en general. Los inconvenientes surgieron desde el Consejo Municipal, a causa de las licitaciones de los espacios gastronómicos, pero esto no repercutió en movilizaciones ni conflictos con ningún sector ciudadano.

Esta renovada espacialidad, denominada "Ciudad Joven", revive sueños y esperanzas para el futuro de la "nueva ciudad" imaginaria y material que se viene construyendo desde los discursos e intervenciones oficiales desde fines de los años noventa: un nuevo espacio público / privado que habilita nuevas prácticas y recorridos urbanos destinados principalmente al consumidor de clase media y al turista.

\section{El polo tecnológico y la reconversión urbanística}

Los polos tecnológicos constituyen otro de los espacios que surgen a consecuencia del proceso de tecnificación digital, que impacta concretamente en las ciudades que buscan ser reconocidas como ciudades creativas e innovadoras. En este punto se destaca el proceso de recualificación emprendido en forma conjunta por los gobiernos local y provincial, para generar en Rosario un espacio que contenga a la industria tecnológica de la ciudad.

Teniendo en cuenta que se consideran polos y parques tecnológicos al agrupamiento o reunión de empresas intensivas en tecnología -particularmente en tecnologías de la información y comunicación (TIC) - que se instalan estableciendo vinculaciones con una universidad o centro de investigación, Rosario resulta un lugar apropiado para el desarrollo de este tipo de emprendimientos, por tratarse de una ciudad con amplia actividad universitaria y empresarial relacionada con las tecnologías. Para Vázquez

ciudad de la cultura y cuna de talentos es constante; pero, por otro lado, en el accionar del gobierno local se atenta sistemáticamente contra los espacios que ofician de semilleros y escenario de los tan alardeados talentos locales. Esto nos conduce a pensar que no se promueve "la cultura", sino determinadas prácticas, productos y espacios culturales que operan como representación del modelo oficial de Rosario.

25 Diario La Capital, 23/7/2014; 24/7/2014

26 Si bien en este trabajo analizamos los imaginarios urbanos desde la perspectiva dominante, en una segunda etapa de la investigación se proyecta estudiar con mayor profundidad las resistencias y los imaginarios ciudadanos emergentes que también constituyen estos espacios que aquí sólo aparecen mencionados para facilitar la contextualización de las reconversiones urbanísticas abordadas. Hay que destacar que estos procesos no se encuentran finalizados, lo cual dificulta el análisis de impacto, usos y apropiaciones de estos nuevos espacios. 
Barquero (1993), en estos espacios existe una concentración espacial, generalmente planificada, de sistemas de comunicación científica y técnica y de infraestructura e investigación, cuyo objetivo es estimular y potenciar la capacidad innovadora de los sistemas productivos de un área determinada. Manuel Castells (1995) afirma que se trata de centros planificados para la promoción de la industria de alta tecnología que redefinen las condiciones y procesos del desarrollo local y regional, formas específicas de concentración territorial de la innovación tecnológica destinadas a generar sinergia científica y aumento de la productividad económica.

Los polos tecnológicos, como nueva institución de la economía flexible del conocimiento, renuevan y materializan las esperanzas colectivas de desarrollo y progreso. Tal es así que en el PER 1998 aparece la idea de impulsar un sector de innovación y tecnología para contribuir al desarrollo de la economía local y regional. En dicho documento, los polos o parques tecnológicos, son concebidos como

una alternativa de integración de recursos económicos, tecnológicos, financieros, físicos y de gestión al servicio de empresas, con el objeto de favorecer la concentración de actividades innovadoras, contribuir a la diversificación sectorial del tejido económico y dinamizar las relaciones de cooperación entre las empresas, los centros de investigación y la Universidad, y por último, pueden incorporar o difundir la cultura de la innovación en el mundo empresarial. (p. 264)

Se sostiene, entonces, que el parque tecnológico debe brindar un entorno favorable para las iniciativas de $\mathrm{I}+\mathrm{D}$ que puedan surgir de sectores tanto públicos como mixtos y privados. A ello se suma la necesidad de contar con un atractivo ambiental, redes básicas de infraestructura urbana -gas natural, energía eléctrica, agua potable y desagües- y redes tecnológicas de fibra óptica y telemática. Además se plantea la necesidad de generar un sistema regional de desarrollo científico tecnológico para aprovechar los recursos humanos que brinda la universidad pública y potenciar el trabajo de las empresas y otros organismos públicos de la región (PER 1998).

El Polo Tecnológico Rosario fue creado en 2003 con el objetivo de "posicionar a Rosario y su región como un centro de referencia internacional en el desarrollo científico y la innovación tecnológica a través de nuevas formas de gestión que articulen los ámbitos públicos, privados y científicos". ${ }^{27}$ Allí convergen empresas del sector privado, universidades y organismos estatales mediante una modalidad de cooperación público-privada. El Polo Tecnológico Rosario trabajó de manera desterritorializada hasta el año pasado cuando se localizó en Zona i- Área Tecnológica Nodo Rosario. Un espacio físico enmarcado en un proyecto de urbanización gestionado mediante convenio urbanístico público-privado a nivel provincial y municipal destinado a contener empresas tecnológicas y favorecer la vinculación con centros de investigación y dependencias estatales. Nos referimos al proyecto "Reconversión del Ex Batallón de Comunicaciones 121”, 28 ubicado en la zona sur de la ciudad

27 Polo Tecnológico Rosario, Visión y Misión [en línea], en http://www.polotecnologico.net/index. $\mathrm{php} /$ institucional/vision-y-mision

28 Ordenanza n. ${ }^{\circ}$ 9027/2012: "Plan especial de reordenamiento urbanístico". Ex Batallón 121. Definición. Ámbito de aplicación. En https://www.rosario.gov.ar/normativa/ver/visualExterna. do?accion $=$ verNormativa\&idNormativa $=88711$ 
(figura 4). En este establecimiento de 30 hectáreas, de gran valor patrimonial, se destinarán 5 hectáreas al área de viviendas para sectores medios, con locales comerciales, a lo que se suma un área de salud, escuelas y una comisaría; 4 hectáreas para el área de industrias tecnológicas; 15 se reservan para un parque público con espejo de agua y paseo peatonal; y en otras 4 se construirá un área deportiva con canchas de fútbol, pileta, gimnasio, el Museo del Deporte y un espacio para la Memoria.

FIgura 4 Proyecto de reconversión Ex Batallón de Comunicaciones 121

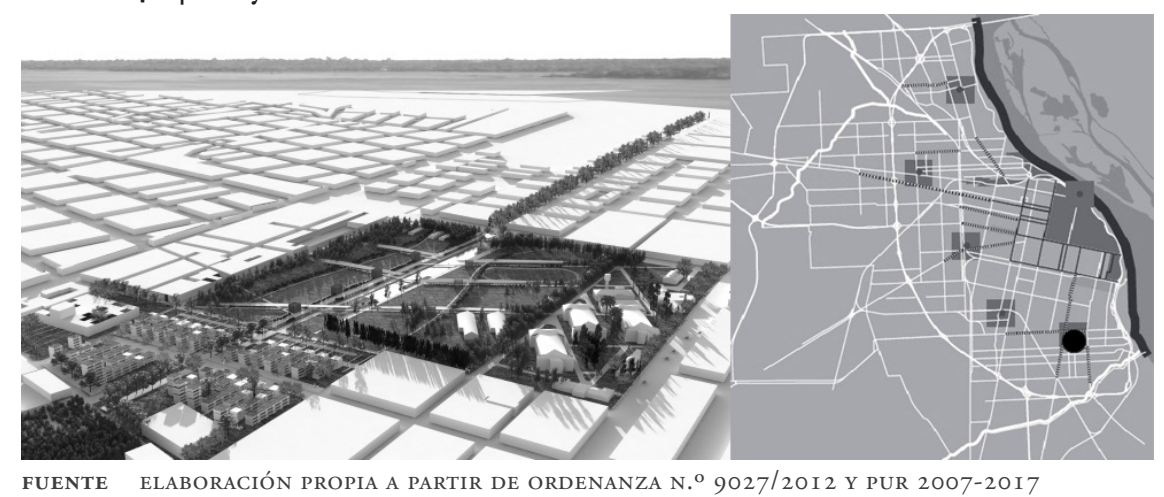

Es importante destacar que este emprendimiento se desarrolla bajo la figura de convenio urbanístico público-privado, instrumento jurídico que formaliza el acuerdo entre el gobierno local y el sector empresarial, a través del cual el Estado cede tierras y habilita la explotación económica de ciertos espacios a cambio de inversión privada en obras públicas. Para todo el proyecto se contará con presupuesto público y numerosas inversiones privadas. En este sentido, para las 1.200 viviendas que se construirán, los desarrolladores inmobiliarios deberán cumplir con la contraprestación de construir la comisaría y las escuelas, abrir cuatro calles, urbanizar la zona de inmuebles carenciados en el barrio e instalar los servicios de luz, agua y cloacas. ${ }^{29}$ Por otra parte, el Museo del Deporte se hará exclusivamente con fondos privados. Allí se piensa dar exclusividad a un sector para homenajear a Lionel Messi, oriundo de la ciudad y cara visible de la marca ciudad "Yo $\bullet$ Rosario", fundamentalmente orientado al turismo, ${ }^{30}$ ya que, como afirmaba la intendenta, "quienes visitan Rosario preguntan por el pasado de Messi y hay que potenciar ese interés". ${ }^{31}$ A tal fin se buscó la inversión y donaciones privadas de empresas y de la Fundación Messi.

Más allá de las diversas áreas que compondrán este nuevo espacio dentro de la ciudad, hay que recordar que el desarrollo del Polo Tecnológico está enmarcado en las políticas de construcción de Rosario como Ciudad Digital y Metrópolis de la

29 Diario La Capital, 10/8/2015. Esto despierta ciertas dudas, ya que en otros emprendimientos público-privados se ha constatado la falta de control del cumplimiento de las contraprestaciones (Diario Rosario/12, 20/10/2012).

30 Para un estudio más detallado de la construcción de Rosario como ciudad turística, se puede consultar Vera (2013b, 2015).

31 Diario La Capital, 31/3/2013. 
Creación y la Innovación (PERM), y se vincula con las tecnologías productivas del capitalismo informacional. ${ }^{32}$ Por lo tanto, el protagonismo que adquiere el "Área Tecnológica Nodo Rosario" (Decreto Provincial n 4261/2012), radica en que sería "el primer distrito tecnológico del país" según el gobernador, y funcionará como plataforma productiva, otorgando innovación y competitividad a la región. ${ }^{33}$ Allí se instalarán 17 empresas del sector, en los edificios históricos pertenecientes originalmente al Ejército Nacional (figura 5), mediante "una iniciativa de vanguardia para la región. La sinergia entre los sectores público y privado, y entre las empresas, permitirá generar el ámbito adecuado para la vinculación del conocimiento con la comunidad y con la producción". ${ }^{34}$ Esta modalidad de inversión público-privada permitirá realizar las obras de recuperación y puesta en valor y funcionamiento de los edificios y, como contraprestación, las empresas tendrán derecho a locación gratuita en el predio por veinte ańos. ${ }^{35}$

\section{FIgURA 5 | Proyecto reconversión para Polo Tecnológico}

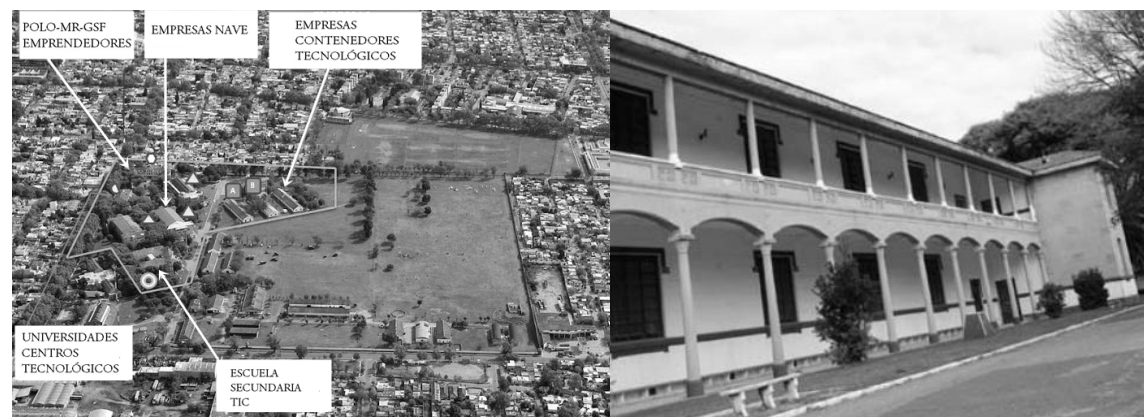

FUENTE ELABORACIÓN PROPIA A PARTIR DE WWW.SANTAFE.GOV.AR Y ARCHIVO DIARIO LA CAPITAL

En este proceso, a diferencia de la reconversión de los antiguos galpones del puerto, sí hubo resistencia y conflictos, principalmente por los modos de uso propuestos. Desde el inicio de este proceso, diversas agrupaciones de Derechos Humanos reclamaron que se construyera un espacio para la Memoria, ya que en ese predio militar se organizaba la logística de detenciones y secuestros; funcionaba como centro clandestino de detención, donde se torturó y asesinó a militantes políticos en la última

32 Además del Polo Tecnológico se impulsó, con el gobierno nacional, la consolidación del Centro Universitario Rosario (CUR) y el Centro Biotecnológico Rosario. Este espacio, situado en el predio de la Universidad Nacional de Rosario en la zona sur de la ciudad, se va apuntalando como nodo científico-tecnológico público, que se complementa con el polo tecnológico y otras instituciones a nivel nacional e internacional, públicas y privadas. El cur se ubica en un terreno que formaba parte de las instalaciones del Ferrocarril Rosario-Puerto Belgrano. Allí, en los últimos ańos se inauguraron nuevos institutos de alta tecnología dependientes del Conicet: el Centro Internacional Franco-Argentino de Ciencias de la Información y de Sistemas, el Instituto de Biología Molecular y Celular de Rosario, Instituto de Física Rosario.

33 Diario La Capital, 10/8/2012.

34 Gobernador Antonio Bonfatti, diario La Capital, 7/7/2013.

35 Diario La Capital, 5/6/2013. 
dictadura cívico-militar (1976-1983). En este caso se llegó a un acuerdo rápidamente y se gestionó un espacio para que la reconversión del lugar no borrara del todo las huellas del pasado y se pudieran realizar actividades culturales de recuperación y conservación de dichas huellas. ${ }^{36}$ Por otra parte, se desplegó un conflicto con un grupo de vecinos que rechazaron la propuesta presentada, llegando a instancias de judicialización para frenar las obras. El principal argumento en contra del plan de reconversión era que se favorecía intereses privados empresariales, y con ello la especulación y el negocio inmobiliario que se desarrollaría por la construcción de viviendas. Como alternativa propusieron crear un jardín botánico y solicitaron la realización de audiencias públicas para decidir de forma participativa los destinos del predio. ${ }^{37}$ Sin un desenlace definitivo, algunas de las obras se frenaron por una medida cautelar. ${ }^{38}$ Otro grupo de actores perjudicados por el plan es la Asociación de Equitación Integral de Rosario, que empleaba el sector de caballerizas y dos hectáreas del predio para desarrollar un programa de equinoterapia para chicos con discapacidades. Denuncian que el plan no contempla sus actividades ni su reubicación, y el conflicto permanece vigente. ${ }^{39}$

Más allá de estas resistencias y las incertidumbres sobre la definición de estos conflictos, una parte de las obras ya fue inaugurada. Y se trata justamente del sector destinado al Polo Tecnológico, denominado "Zona I", 40 como emblema y "orgullo para Rosario". Este proyecto se centra en la innovación, y por ello desde el gobierno local consideran que todo lo que tenga que ver con el futuro desarrollo de toda la comunidad se gestará en ese espacio. ${ }^{41}$ De este modo, "la innovación" se emplea y expone como sentido aglutinante de deseos y expectativas que se presentan intentando desdibujar no solo el contenido político del término, sino también los matices, los desacuerdos y los cuestionamientos a un modelo urbano que si bien responde al imaginario dominante, no es homogéneo.

Para finalizar, es necesario destacar que aunque muchos procesos de recualificación están atravesados por el imaginario urbano dominante -el cual en muchos casos es de carácter global o transnacional-, incluso dentro de la misma ciudad dichos procesos responden a lógicas diferentes. Esto se debe a que están estrechamente anclados en una historia, una territorialidad y una identidad cultural particular. Hay casos donde la renovación de ciertos espacios de la ciudad es aceptada por la mayoría, sin encontrar resistencias, mientras que otros procesos pueden despertar desde grandes movimientos de disputas por los espacios, hasta instancias de acuerdo y negociación.

36 Diario La Capital, 31/8/2014.

37 Diario La Capital, 3/12/2012, 23/3/2013, 27/3/2013.

38 Diario La Capital, 7/4/2015.

39 Diarios El Ciudadano 29/9/2014, y La Capital 10/2/2015.

40 Se constituyó como Parque Tecnológico a través del N4261/2012. El primer edificio recualificado fue inaugurado el 26/11/2015.

41 Palabras de la intendenta Fein y el secretario de Ciencia, Técnica e Innovación Asteggiano. La Capital, 22/5/2015. 


\section{Conclusiones}

Como se pudo analizar, la innovación es una significación dominante y potente, porque vehiculiza deseos y sueños colectivos que se renuevan, alimentando la idea de progreso social a través del desarrollo tecnológico. Se presenta como la energía, el motor y la promesa de un futuro mejor y se afianza como nueva ensońación social. Sin embargo, no es absolutamente nueva en cuanto a gran parte de los sentidos que soporta. Por un lado, está compuesta por ideas nuevas vinculadas a los tipos de productos o bienes y a las asociaciones posibles entre diversos actores; pero, por otro, recupera y resignifica sentidos del imaginario moderno, como la idea de progreso, evolución, optimismo tecnológico, racionalidad técnica y futuro. Junto con ello, se establece la ciudad como nodo central de este proceso, asimilando la difundida creencia de que las ciudades que no estén a la altura de las innovaciones científico-tecnológicas contemporáneas quedarán fuera del nuevo orden mundial. Esto impacta en el modelo urbano que se delinea en función de determinadas significaciones, entre ellas creatividad, innovación, ciencia y tecnología como las variables de competitividad y desarrollo contemporáneas.

En este marco, se pudo analizar la resonancia del discurso empresarial en el político, donde se comprueba la incorporación de herramientas neoliberales en la construcción del nuevo modelo urbano, consecuente con los modelos internacionales que promueven tanto los consultores, como académicos, empresas y organismos internacionales. A partir de estas herramientas técnicas, discursividades y acciones públicas y privadas se construye determinado modelo de ciudad que, desde la década de los noventa, como se evidencia en los planes y las políticas analizadas, se co-construye en mayor parte con las corporaciones empresariales de la ciudad a partir de los convenios público-privados, y no tanto con los vecinos, como se promueve desde el discurso de la participación ciudadana. La empresa entra en el Estado ya no solo a través de las licitaciones públicas, que son herramientas de la administración municipal moderna, sino a partir de algo más profundo, como es la matriz de significaciones sociales. Esto se percibe también en la imagen de ciudad como empresa, como industria creativa, ya que gran parte de la inversión en los procesos de reconversión de la ciudad son aportados por el sector privado, evidenciando la dependencia del sector estatal para construir la "nueva ciudad" que -en el caso analizado- busca hacer de Rosario una ciudad más rentable. La flexibilidad no solo domina el campo económico, sino también el social y cultural, al plantear acuerdos que se presumen horizontales e igualitarios entre actores heterogéneos, con intereses y conflictividades que parecen ser desconocidos desde las discursividades analizadas.

A partir de la ciudad industrial con que se representó a Rosario se construye la ciudad innovadora; sobre los restos del puerto y los ferrocarriles, se instalan las industrias creativas, culturales y centros científicos; sobre las estructuras militares del Estado-nación, el polo tecnológico.

En el estudio de caso se evidencia que el modelo de innovación dominante en el imaginario social repercute en los modelos espaciales de los procesos de reconversión, donde predominan las intervenciones focalizadas que generan nuevas centralidades, espacios muchas veces cerrados sobre sí mismos. Si bien en los planes la perspectiva 
sobre la innovación aparece matizada con el calificativo "social”, es ineludible la impronta economicista, ya que el objetivo final que se persigue es la generación de valor y recursos económicos que redunden en beneficios para la ciudad. Es decir, desde la discursividad oficial existe una mirada clásica vinculada a la economía de la innovación lineal y, a su vez, se defiende el modelo de triple hélice -Estado, universidad, empresas- dejando al ciudadano por fuera del proceso innovador, al contrario de lo que postula la perspectiva de cuádruple hélice. En Rosario, esto repercute en los rumbos que transitaron los procesos de reconversión urbana, en los cuales las decisiones y lineamientos estratégicos se realizaron sin la participación de los ciudadanos implicados en cada contexto de actuación. Esto se comprueba en la ausencia de acuerdos concretos con sectores sociales cuyos intereses no estaban contemplados como parte de los procesos innovadores o no resultaban redituables al proyecto original.

La hegemonía del imaginario de la innovación como medio para incrementar el valor de las ciudades, y con ello mejorar su situación económica, tiene serias consecuencias sobre ellas. En primer término, porque se orienta a reforzar los mecanismos del capitalismo actual que, por definición, no es inclusivo ni integrador. Esto se traduce concretamente en los tipos de espacialidades urbanas construidas o recualificadas en procesos que no contemplan el contexto social, histórico y cultural del lugar, y que profundizan la fragmentación social y el acceso poco equitativo a los nuevos enclaves urbanos. Otro de los efectos que se destacan en el fenómeno analizado es un creciente proceso de estetización urbana, que impacta no solo en el aspecto estilístico y arquitectónico de las materialidades intervenidas, sino también en las subjetividades, prácticas y estilos de vida. Es en este sentido que la innovación como argumentación trasciende el campo discursivo para hacerse cuerpo, hábito y lugar, donde el deseo y las creencias en el diseńo, la creatividad innovadora, la ciencia y la tecnología se condensan en modos de vida y consumos culturales específicos que no implican la heterogeneidad de los sujetos urbanos contemporáneos.

\section{Referencias bibliográficas}

Alonso, A. (2013). Ética en la innovación y el movimiento Open. Isegoría (48), 95-110. http:// doi.org/10.3989/isegoria.2013.048.05

Alonso, L. \& Fernández Rodríguez, C. (2011). La innovación social y el nuevo discurso del Management: limitaciones y alternativas. ARBOR. Ciencia, Pensamiento y Cultura, 187(752), 1133-1145. http://doi.org/10.3989/arbor.2011.752n6009

Augé, M. (2012). Futuro. Buenos Aires: Adriana Hidalgo.

Bell, D. (1964 [1960]). El fin de las ideologías. Madrid: Tecnos.

Cabrera, D. (2006). Lo tecnológico y lo imaginario. Las nuevas tecnologias como creencias y esperanzas colectivas. Buenos Aires: Biblos.

Capel, H. (2007). El debate sobre la construcción de la ciudad y el llamado Modelo Barcelona. Scripta Nova. Revista Electrónica de Geografía y Ciencias Sociales, 11(233). http://www. ub.edu/geocrit/sn/sn-233.htm 
Cassián Yde, N. (2012). De qué está hecha una ciudad creativa. Una propuesta para abordar la cultura, el ocio y la creatividad en la urbe contemporánea. Athenea Digital, 12(1), 169-190. http://www.raco.cat/index.php/Athenea/article/view/250922

Castells, M. (1995 [1989]). La ciudad informacional. Tecnologias de la Información, reestructuración económica y el proceso urbano-regional. Madrid: Alianza.

Castells, M. (1997). La era de la información. Economía, sociedad y cultura. Madrid: Alianza.

Castoriadis, C. (2003). La institución imaginaria de la sociedad. Buenos Aires: Tusquets.

Comisión Económica para América Latina y el Caribe (Cepal). (2007). Cinco piezas de política de desarrollo productivo. Serie Desarrollo Productivo, 176 [LC/L.2704-P]. Santiago, Chile: onU-Cepal. http://repositorio.cepal.org/bitstream/handle/11362/4571/1/S070 0230_es.pdf

Delgado, M. (2007). Sociedades movedizas. Pasos hacia una antropología de las calles. Barcelona: Anagrama.

Díaz, E. (2003). Efectos socioculturales del desarrollo tecnocientífico. Estudios Sociológicos de El Colegio de México, 21(62), 445-461. http://estudiossociologicos.colmex.mx/index. $\mathrm{php} / \mathrm{es} / \mathrm{article} / \mathrm{view} / 566$

Echeverría (2013). La retórica de la innovación. Revista Iberoamericana de Argumentación (7), 1-12. http://revistas.uned.es/index.php/RIA/article/view/11232

Echeverría, J. \& Merino, L. (2011). Cambio de paradigma en los estudios de innovación: el giro social de las políticas europeas de innovación. ARBOR - Ciencia, Pensamiento y Cultura, 187(752), 1031-1043. http://doi.org/10.3989/arbor.2011.752n6002

Fernández Rodríguez, C. (2007). El discurso del management: tiempo y narración. Madrid: Centro de Investigaciones Sociológicas (cis).

Finquelievich, S. (Coord.). (2007). La innovación ya no es lo que era. Impactos meta-tecnológicos en las áreas metropolitanas. Buenos Aires: Dunken. http://www.e-derecho.cl/downloads/ innovacion.pdf

Florida, R. (2009) Las ciudades creativas. Barcelona: Paidós.

Fonseca, A. \& Kageyama, P. (Orgs.)(2009). Creative city perspectivas. São Paulo: Garimpo de Soluçôes and Creative Cities Productions. http://dlc.dlib.indiana.edu/dlc/ handle/10535/5520

Fukuyama, F. (1992 [1989]). El fin de la historia y el último hombre. Barcelona: Planeta.

García Canclini, N. (2002). Las industrias culturales y el desarrollo de los países americanos [en línea]. www.oas.org/udse/espanol/documentos/1hub2.doc

Godin, B. (2010). Innovation without the word: William F. Ogburn's contribution to technological innovation studies. Working Paper no. 5, Project on the Intellectual History of Innovation, Montreal: Publicado en Minerva, 48(3), 2010, 277-307. http:// www.csiic.ca/PDF/IntellectualNo5.pdf

Gurruxtaga, A. (2011). Condiciones y condicionamientos de la innovación social. ARBOR Ciencia, Pensamiento y Cultura, 187(752), 1045-1064. http://doi.org/10.3989/ arbor.2011.752n6003

Herrera Medina, E., Bonilla Estévez, H. \& Molina Prieto, L. (2013). Ciudades creativas: ¿paradigma económico para el diseño y la planificación urbana? Bitácora Urbano Territorial, 1(22), 11-20. http://www.revistas.unal.edu.co/index.php/bitacora/article/ view/11-20 
Lacarrieu, M. (2010). Ciudades latinoamericanas. Desafíos y limitaciones de los procesos de recualificación cultural: ¿globales/transnacionales, regionales, nacionales y/o locales? Revista PraiaVermelha; 20(2), 135-156. http://docplayer.com.br/17068244-Revistapraiavermelha-revista-de-servico-social-programa-de-pos-graduacao-da-escola-deservico-social.html

Lerner, J. (2009). Every city can be a creative city. En A. Fonseca \& P. Kageyama (Orgs.), Creative city perspectivas (pp. 31-36). Sáo Paulo: Garimpo de Soluções and Creative Cities Productions. http://dlc.dlib.indiana.edu/dlc/handle/10535/5520

Mercado de Industrias Culturales Argentinas (MICA). (2013). MICA 2013 - Mercado de Industrias Culturales Argentinas [en línea]. https://www.taringa.net/post/info/16597162/MICA2013---Mercado-de-Industrias-Culturales-Argentinas.html

Mumford, L. (2011). El mito de la máquina. Logroño (La Rioja), España: Pepitas de Calabaza.

Municipalidad de Rosario (1998). Plan Estratégico Rosario 1998. http://www.rosario.gov.ar/ sitio/verArchivo?id=4718\&tipo=objetoMultimedia

Municipalidad de Rosario (2010). Plan Estratégico Rosario Metropolitana | PERM+10. http:// echerosario.blogspot.cl/2010/05/plan-estrategico-rosario-metropolitana_23.html

Municipalidad de Rosario (2011). Plan Urbano Rosario 2007/2017. http://www.rosario. gov.ar/web/ciudad/planeamiento-urbano/plan-urbano-rosario/libro-plan-urbanorosario-2007/2017

Nowotny, H. (2011). La curiosidad insaciable. La innovación en un futuro incierto. Barcelona: Universitat Oberta de Catalunya (UOC).

Peters, M. (2008). Education, creativity and the economy of passions. En M. Peters, S. Marginson \& P. Murphy (Eds.), Creativity and the global knowledge economy (pp. 125148). Nueva York: Peter Lang.

Quartesan, A., Romis, M. \& Lanzafame, F. (2007). Las industrias culturales en América Latina y el Caribe: desafios y oportunidades [En línea]. Washington, D.c.: Banco Interamericano de Desarrollo (BID). https://publications.iadb.org/handle/11319/5437?localeattribute $=$ en

Sassen, S. (1991). La ciudad global. Nueva York, Londres, Tokio. Buenos Aires: Eudeba.

Schiavo, E., Baumann, P., Dos Santos Nogueira, C. \& Vera, P. (2013). Estudio sobre indicadores TIC en instituciones científicas y tecnológicas de Iberoamérica. Informe final. Observatorio Iberoamericano de la Ciencia, la Tecnología y la Sociedad (cTs), Organización de Estados Iberoamericanos (OEI)-Agencia Española de Cooperación Internacional para el Desarrollo (AECID). http://bit.ly/2im2ppT

Schmucler, H. (1997). Memoria de la comunicación. Buenos Aires: Biblio.

Schweinheim, G. F. (2011). ¿Un nuevo desarrollo en América Latina? Implicancias en las políticas públicas, el Estado y la Administración. Revista del CLAD Reforma y Democracia (49), 57-98. http://www.redalyc.org/articulo.oa?id=357533681002

Sennet, R. (2013). Artesanía, tecnologia y nuevas formas de trabajo. Buenos Aires: Katz.

Serra, A. (2010). Citilabs: ¿Qué pueden ser los laboratorios ciudadanos? La Factoría (45-46).

Tuomi, I. (1999). Corporate knowledge: Theory and practice of intelligent organization. Helsinki: Metaxis. 
Vázquez Barquero, A. (1993), Política económica local. Madrid: Pirámide.

Vera, P. (2013a). El progreso como ensońación social. Espacialidades de la modernidad en Rosario, Argentina. Anuario Revista Digital de la Escuela de Historia [Universidad Nacional de Rosario] (25), 57-90. http://rephip.unr.edu.ar/handle/2133/3673

Vera, P. (2013b). Imaginarios urbanos y procesos de urbanización en las nuevas ciudades turísticas. El caso de Rosario, Argentina. Revista Bitácora Urbano Territorial, 22(1), 153-162.

Vera, P. (2014). Imaginarios urbanos y tecnológicos en los procesos de construcción material y simbólica de la ciudad moderna y contemporánea. El caso de la ciudad de Rosario en el contexto de las metrópolis del interior de Argentina. Tesis doctoral, Doctorado en Ciencias Sociales y Humanas, Universidad Nacional de Quilmes, inédita.

Vera, P. (2015). Estrategias patrimoniales y turísticas: su incidencia en la configuración urbana. El caso Rosario, Argentina. Territorios (33), 83-102. ttp://doi.org/10.12804/ territ33.2015.04"

Videla, O. (1999). Ambiente urbano e idea de la ciudad. Las imágenes de los viajeros en Rosario a mediados del siglo XIx. Papeles de Trabajo, 2(1) (Centro de Estudios Sociales Regionales [CESOR], Facultad de Humanidades y Artes, Universidad Nacional de Rosario).

Vieira Pereira, V. (2015). Inovação e desenvolvimento regional: uma crítica a partir de Marx. Ponencia presentada en el Xx Encontro Nacional de Economia Política, organizado por la Sociedade Brasileira de Economia Política (SEP), 26-29 de mayo de 2015, Paraná, Brasil.

Yúdice, G. (2008). Modelos de desarrollo cultural urbano: ¿gentrificación o urbanismo social? Alteridades, 18(36), 47-61. http://www.redalyc.org/articulo.oa?id=74716004005 